\title{
Climate-driven marine silicate weathering off Peru
}

\author{
SONJA GEILERT ${ }^{1}$, PATRICIA GRASSE ${ }^{2}$, DIETER GARBE- \\ SCHÖNBERG $^{3}$, ANDEW DALE $^{1}$ AND STEFAN SOMMER ${ }^{1}$ \\ ${ }^{1}$ GEOMAR Helmholtz Centre for Ocean Research Kiel \\ ${ }^{2}$ German Centre for Integrative Biodiversity Research (iDiv) \\ Halle-Jena-Leipzig \\ ${ }^{3}$ CAU Kiel University \\ Presenting Author: patricia.grasse@idiv.de
}

Marine silicate weathering is controlled by the competition of forward and reverse weathering reactions. The first reaction produces alkalinity and consumes $\mathrm{CO}_{2}$ by dissolution of reactive minerals, whereas the second reaction counteracts this process by consuming alkalinity and releasing $\mathrm{CO}_{2}$ during the formation of authigenic aluminosilicates. The factors controlling these processes are still barely understood. In this study, we investigated pore fluids from the Peruvian margin using $\mathrm{Si}$ isotopes $\left(\delta^{30} \mathrm{Si}\right)$ and $\mathrm{Ge} / \mathrm{Si}$ ratios to better understand silicate weathering in marine sediments. We studied a shelf site at two time intervals (2013 and 2017) at ca. $80 \mathrm{~m}$ water depth, a site within the Oxygen Minimum Zone (OMZ) at ca. $300 \mathrm{~m}$ (bottom water $\mathrm{O}_{2}<$ detection limit), and a site below the $\mathrm{OMZ}$ at ca. 750 $\mathrm{m}$. Additionally, the above-mentioned parameters were also measured in benthic incubation chambers to identify $\delta^{30} \mathrm{Si}$ and $\mathrm{Ge} / \mathrm{Si}$ ratios in the benthic fluxes. The $\delta^{30} \mathrm{Si}$ values in the pore fluids ranged from $+0.53 \%$ to $+3.72 \%$, showing the highest $\delta^{30} \mathrm{Si}$ and $\mathrm{Ge} / \mathrm{Si}$ ratios (1.01 to $2.87 \mu \mathrm{mol} \mathrm{mol}^{-1}$ ) at the shelf site sampled in 2017. Only at this shelf site was the $\delta^{30} \mathrm{Si}$ of the benthic Si flux distinguishable from the background seawater value, despite a lower Si flux compared to the other stations.

The shelf site sampled in 2017 was characterized by pronounced authigenic aluminosilicate formation (increase from +24 to $+60 \%$ ) compared to 2013 , most likely triggered by an enhanced delivery of terrigenous reactive metal(hydr)oxides to the ocean. Increased terrigenous material supply can be explained by a coastal El Niño event and extensive precipitation (e.g. Echevin et al., 2018) that took place before the fieldwork in 2017. Consequently, marine silicate weathering and local climate may be strongly linked. Our results suggest that the uptake or release of cations and $\mathrm{CO}_{2}$ associated with marine silicate weathering reactions can be highly dynamic, with rapid adjustment to local climatic factors.

\section{References}

Echevin V., Colas F., Espinoza-Morriberon D., Vasquez L., Anculle T. and Gutierrez D. (2018), Front. Mar. Sci. 5, 1-16. 